\title{
$\beta$-Hydroxy carbocation intermediates in solvolyses of di- and tetra-hydronaphthalene substrates
}

\author{
Jaya S. Kudavalli and Rory A. More O'Ferrall ${ }^{*}$
}

\section{Full Research Paper}

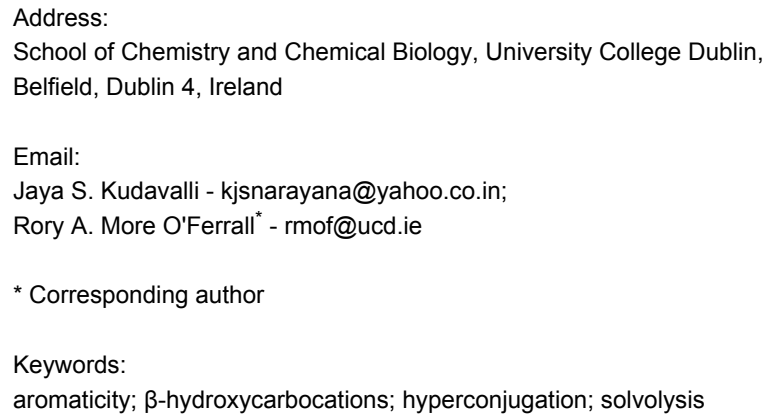

Beilstein J. Org. Chem. 2010, 6, 1035-1042.

doi:10.3762/bjoc.6.118

Received: 02 September 2010

Accepted: 25 October 2010

Published: 03 November 2010

Guest Editor: J. Murphy

() 2010 Kudavalli and More O'Ferrall; licensee Beilstein-Institut. License and terms: see end of document.

\begin{abstract}
Solvolysis of trichloroacetate esters of 2-methoxy-1,2-dihydro-1-naphthols shows a remarkably large difference in rates between the $c i s$ and trans isomers, $k_{\text {cis }} / k_{\text {trans }}=1800$ in aqueous acetonitrile. This mirrors the behaviour of the acid-catalysed dehydration of cis- and trans-naphthalene-1,2-dihydrodiols to form 2-naphthol, for which $k_{\text {cis }} / k_{\text {trans }}=440$, but contrasts with that for solvolysis of tetrahydronaphthalene substrates, 1 -chloro-2-hydroxy-1,2,3,4-tetrahydronaphthalenes, for which $k_{\text {cis }} / k_{\text {trans }}=0.5$. Evidence is presented showing that the trans isomer of the dihydro substrates reacts unusually slowly rather than the cis isomer unusually rapidly. Comparison of rates of solvolysis of 1-chloro-1,2,3,4-tetrahydronaphthalene and the corresponding (cis) substrate with a 2 -hydroxy group indicates that a $\beta-\mathrm{OH}$ slows the reaction by nearly 2000 -fold, which represents a typical inductive effect characteristic also of cis-dihydrodiol substrates. The slow reaction of the trans-dihydrodiol substrate is consistent with initial formation of a $\beta$-hydroxynaphthalenium carbocation with a conformation in which a $\mathrm{C}-\mathrm{OH}$ occupies an axial position $\beta$ to the carbocation centre preventing stabilisation of the carbocation by $\mathrm{C}-\mathrm{H}$ hyperconjugation, which would occur in the conformation initially formed from the cis isomer. It is suggested that $\mathrm{C}-\mathrm{H}$ hyperconjugation is particularly pronounced for a $\beta$-hydroxynaphthalenium ion intermediate because the stability of its no-bond resonance structure reflects the presence of an aromatic naphthol structure.
\end{abstract}

\section{Introduction}

Cis-arenedihydrodiols are products of fermentation of aromatic molecules by mutant strains of soil bacteria containing dioxygenase enzymes such as Pseudomonas putida UV4 [1]. A characteristic reaction they undergo is acid-catalysed dehydration to form phenols [2], as illustrated for benzene-1,2-dihydrodiol in Scheme 1.
A surprising finding is that the reactivity of cis-dihydrodiols is much greater than that of the synthetically accessible trans isomers, e.g., $k_{\text {cis }} / k_{\text {trans }}=4500$ for cis- and trans-benzene dihydrodiols (1), despite the expectation that the two reactions proceed through a common $\beta$-hydroxycarbocation intermediate (2) [3]. This contrasts with reactions of cis- and trans-dihydro- 


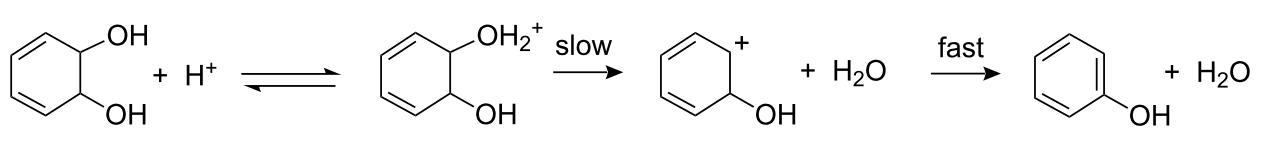

1

2

Scheme 1: Mechanism of dehydration of benzene-1,2-dihydrodiol.

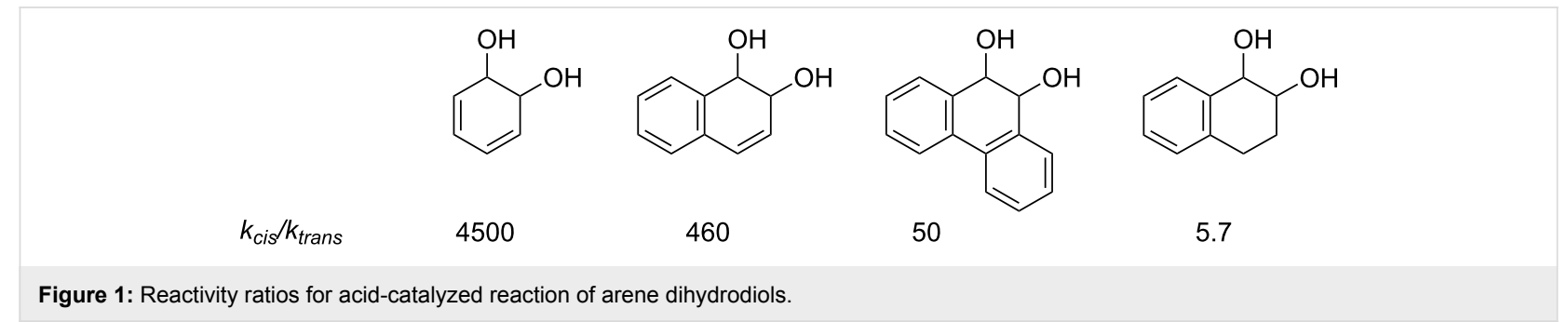

diols of non-aromatic double bonds for which only a small advantage for the cis-diol is observed. Indeed, the cis/trans rate ratio decreases regularly as the aromaticity of the double bond decreases, as shown for the dihydrodiols of benzene, naphthalene $(1,2)$, phenanthrene $(9,10)$ and 3,4-dihydronaphthalene in Figure 1 [3].

The purpose of the present work was to determine whether the same differentials apply to solvolysis reactions of dihydrodiol derivatives for which one of the hydroxy groups has been converted to a more reactive leaving group. In the case of benzene dihydrodiol it is hard to functionalise the hydroxy group without triggering aromatisation to phenol, at least in the case of the cis-diol. The same is true of the cis-1,2-dihydrodiol of naphthalene. However, prior methylation of the 2-hydroxy group of this substrate led to the preparation of cis- and trans-1trichloroacetoxy-2-methoxy-1,2-dihydronaphthalenes (3) which were stable enough to be isolated and purified (Figure 2). This allowed us to compare a ratio of rate constants for the solvolyses of these two isomers with the corresponding ratio for solvolyses of cis-and trans-1-chloro-2-hydroxy-1,2,3,4-tetrahydronaphthalene (1-chloro-2-tetralol, 4), which are similar in structure but lack a 3,4-double bond and yield carbocations which cannot undergo deprotonation to form aromatic products.

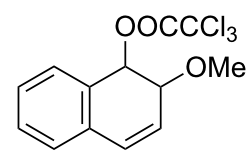

3

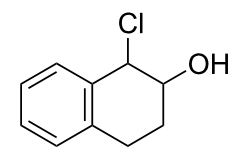

4<smiles>ClC1CCCc2ccccc21</smiles>

5
Figure 2: Substrates for solvolysis measurements.
Finally, to allow the influence of the $\beta$-hydroxy group on the rate of solvolysis to be assessed, a rate constant for solvolysis of the corresponding tetrahydronaphthalene substrate lacking a $\beta$-hydroxy group, namely 1 -chloro-1,2,3,4-tetrahydronaphthalene (5), has been measured.

\section{Results}

\section{Cis- and trans-1-trichloroacetoxy-2-methoxy- 1,2-dihydro-naphthalenes (3)}

Rate constants for solvolyses of cis- and trans-1-trichloroacetoxy-2-methoxy-1,2-dihydronaphthalene (3) were measured spectrophotometrically in aqueous acetonitrile and were recorded for different solvent compositions (Table 1). Addition of the acetonitrile to water solubilised the substrates which are precipitated in pure water. A rate constant in water for the cissubstrate was extrapolated from measurements at different solvent compositions plotted as $\log k$ against $Y_{\mathrm{OTs}}$ (Supporting Information File 1, Figure S1) [4,5]. For the trans isomer the solvolysis was too slow for measurements over a wide range of solvent compositions and rate constants could conveniently be measured only for 10 and $20 \%(\mathrm{v} / \mathrm{v})$ acetonitrile. A rate constant in water was crudely extrapolated from the ratio of rate constants for the cis and trans isomers at these two solvent compositions. Values in water are shown in brackets in Table 1.

In the case of the more slowly reacting trans isomer there was a competing hydrolysis of the trichloroacetate ester group to give trans-2-methoxy-1,2-dihydro-1-naphthol (6-trans), as shown in Scheme 2. The fraction of hydrolysis was determined by HPLC and was found to increase with increasing water content and amounted to $67 \%$ in $10 \%$ acetonitrile.

Surprisingly, $10 \%$ of the hydrolysis product was also identified in the products from solvolysis of the cis-trichloroacetate 
Table 1: Rate constants for solvolysis of cis- and trans-1-trichloroacetoxy-2-methoxy-1,2-dihydronaphthalene (3) in acetonitrile-water mixtures at $25^{\circ} \mathrm{C}$.

\begin{tabular}{|c|c|c|c|c|c|}
\hline$\% \mathrm{MeCN}$ & $\begin{array}{c}10^{3} k_{\mathrm{obs}}\left(\mathrm{s}^{-1}\right) \\
\text { cis }\end{array}$ & $\begin{array}{c}10^{3} k_{\text {obs }}\left(\mathrm{s}^{-1}\right) \\
\text { trans }\end{array}$ & $\begin{array}{c}\% \text { solvolysis } \\
\text { trans }\end{array}$ & $Y_{\text {OTs }}^{b}$ & $k_{\text {cis }} / k_{\text {trans }}$ \\
\hline 50 & 0.63 & & & 1.4 & \\
\hline 40 & 0.84 & & & 1.8 & \\
\hline 30 & 2.31 & & & 2.3 & \\
\hline 20 & 6.75 & $0.0053^{c}$ & 33 & 3.2 & $1.28 \times 10^{3}$ \\
\hline 10 & 20.1 & $0.0122^{c}$ & 16 & 3.7 & $1.65 \times 10^{3}$ \\
\hline 0 & (35) & $(0.019)^{\mathrm{C}}$ & & 3.9 & $\left(\sim 1.8 \times 10^{3}\right)$ \\
\hline
\end{tabular}

aMeasured by HPLC. ${ }^{b}$ Values interpolated from measurements recorded for solvent mixtures made up by weight from [5] ${ }^{\mathrm{C} R a t e}$ constant for solvolysis corrected for competing hydrolysis.

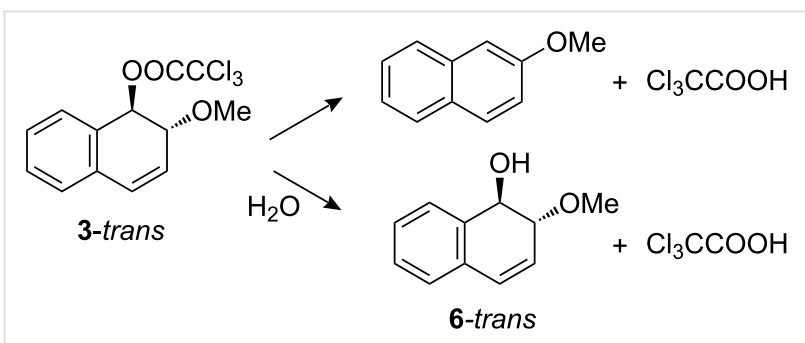

Scheme 2: Products of solvolysis and (ester) hydrolysis of trans-1-trichloroacetoxy-2-methoxy-1,2-dihydronaphthalene.

(3-cis). This was unexpected because the solvolysis of this substrate is more than one thousand times faster than that of its trans isomer whereas the rate of hydrolysis should remain practically unchanged. In so far as the hydrolysis product was not present in the reactants and the fraction of hydrolysis was independent of solvent composition, the most likely explanation would seem to be that the hydrolysis is catalysed by the cismethoxy group.

The supplementary data record salt effects for the solvolysis of the cis-trichloroacetate ester (3-cis). For sodium acetate, the rate in $20 \%$ acetonitrile increased by a factor of close to two at a concentration of $0.4 \mathrm{M}$, whilst smaller effects were observed for both sodium perchlorate and sodium azide. A little surprisingly, sodium trichloroacetate showed a small negative salt effect leading approximately to a halving of the rate at a salt concentration of $1 \mathrm{M}$. This is unlikely to be a common ion effect, because loss of a $\beta$-proton from a naphthalenium ion intermediate to form the aromatic product (naphthol) is expected to be too fast $[6,7]$. This conclusion is confirmed by the lack of saturation of the effect and the normal salt effects observed for sodium acetate and sodium azide, which would be expected to trap a carbocation intermediate more effectively than the trichloroacetate anion. The normal salt effect exerted by the sodium azide also confirms that the solvolysis proceeds via the formation of a carbocation intermediate rather than by an $\mathrm{S}_{\mathrm{N}} 2$ mechanism.

\section{1-Chloro- and 1-chloro-2-hydroxy-1,2- tetrahydronaphthalenes}

Rate constants for solvolysis of cis- and trans-1-chloro-2hydroxy-1,2,3,4-tetrahydronaphthalenes (4) were measured in aqueous solution by monitoring small but easily measurable changes in the UV absorbance. Values obtained were $8.1 \times 10^{-3}$ $\mathrm{s}^{-1}$ and $1.6 \times 10^{-2} \mathrm{~s}^{-1}$ for the cis and trans isomers, respectively. Product analyses showed the formation of practically the same ratio of cis to trans diols from cis and trans reactants together with a small amount of 2-tetralone. The product distribution for the trans isomer is shown in Scheme 3. The corresponding figures for the cis isomer are $76 \%$ cis and $20 \%$ trans dihydrodiols plus $4 \%$ 2-tetralone.

The similarity of the product ratios for cis and trans isomers argues for a common carbocation intermediate in the solvolysis reactions. The possibility of significant reaction via an epoxide

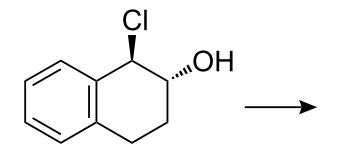

4-trans<smiles>OC1CCc2ccccc2C1O</smiles>

cis<smiles>OC1CCc2ccccc2C1O</smiles>

trans

$20.5 \%$<smiles>O=C1CCc2ccccc2C1</smiles>

$3.5 \%$

Scheme 3: Products of solvolysis of trans-1-chloro-2-hydroxy-1,2,3,4-tetrahydronaphthalene. 
intermediate is made unlikely by the predominant formation cisdihydrodiol from the trans-chlorohydrin reactant and the formation of similar products from both isomers. Evidence of partial reaction via an epoxide intermediate in buffers at higher $\mathrm{pH}$, which could favour epoxide formation, will be reported elsewhere [8].

For the 1-chlorotetrahydronaphthalene (5), solvolysis in water could not be measured directly, but a value of $14 \mathrm{~s}^{-1}$ was obtained by extrapolation of a plot of $\log k$ against $Y_{\mathrm{OTs}}$ for aqueous acetonitrile mixtures (Supporting Information File 1, Figure S1). The measured and extrapolated rate constants in water for the five substrates studied are summarised under the appropriate structures in Figure 3.

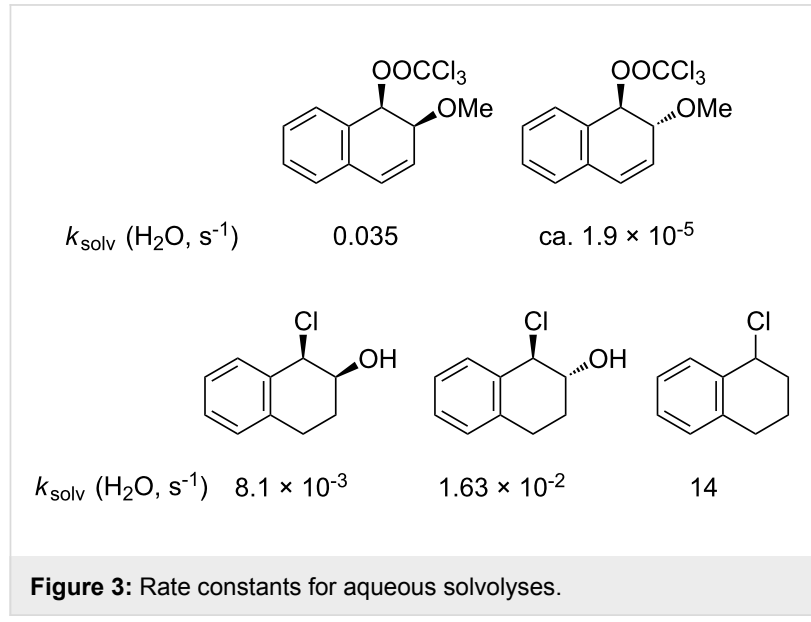

\section{Discussion}

The major conclusion to be drawn from the measurements described above is that solvolysis of cis and trans 1-trichloroacetoxy-2-methoxy-1,2-dihydronaphthalenes (3) show an even larger advantage for reaction of the $c i s$ isomer, with $k_{\text {cis }} / k_{\text {trans }}=$ $\sim 1800$, than the acid-catalysed reaction of the corresponding dihydrodiols $7\left(k_{c i s} / k_{\text {trans }}=440\right)$ or the similar 2-methoxy-1,2dihydronaphthols $8\left(k_{\text {cis }} / k_{\text {trans }}=415\right)$ [8]. Moreover, this advantage is lost for the chlorohydrins of the non-aromatic double bond of 3,4-dihydronaphthalene (as it is for the corresponding dihydrodiol). These measurements are summarised in Figure 4.

It is clear that the $\beta-\mathrm{OH}$ and $\beta-\mathrm{OMe}$ substituents exert a profound influence on the relative reactivity of cis- and transdihydrodiol isomers and their derivatives functionalised at the 1-position when the dihydrodiol is derived from an aromatic double bond. A question that arises is: does this selectivity derive from an unusually reactive $c i s$ isomer or an unusually unreactive trans isomer? Evidence on this point comes from examining the effect of the $\beta$-hydroxy group on the rate of reactions of the cis and trans isomers.

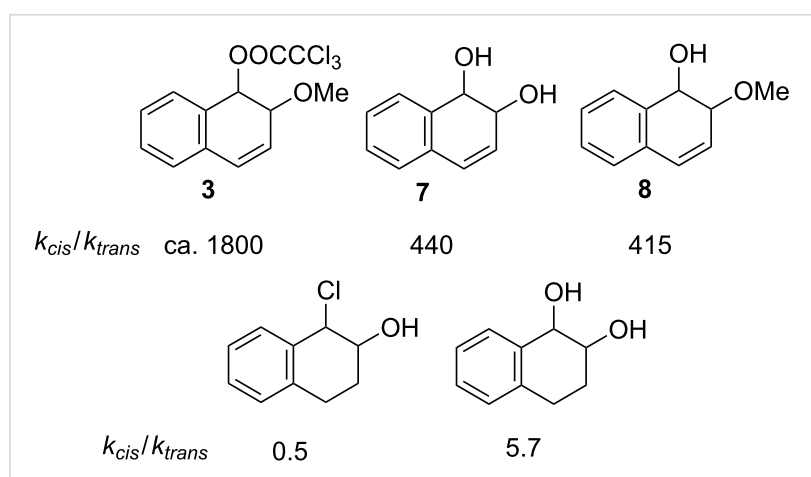

Figure 4: Cis/trans reactivity ratios for $\beta$-hydroxycarbocation forming reactions.

Comparison of rate constants for the aqueous solvolysis of cisand trans-1-chloro-2-hydroxy-1,2-dihydronaphthalenes (4) with the rate constant for the corresponding substrate lacking a hydroxy group (5) in Figure 3 shows that the hydroxy slows the rate by a factor of 860 in the case of the trans isomer and 1700 in the case of the cis. These rate retardations seem a little large when compared with early estimates of the effect of a $\beta$-hydroxy or methoxy group in solvolysis reactions, which gave $k_{\mathrm{H}} / k_{\mathrm{OH}} \sim 100$ [9-11]. However, for $\beta$-oxy substituents it is difficult to separate a rate-retarding (inductive) effect from a competing acceleration arising from participation of oxygen as a neighbouring group $[12,13]$.

As shown in Table 2, more recent estimates of the rate-retarding effect have been based on incorporating oxygen into a structural framework which prevents its participation as a neighbouring group. An example of this constraint is provided by comparison of solvolyses of the exo- and endo-norbornyl brosylate with an oxygen atom at the 7-position (9) with the corresponding substrate lacking an oxygen. This leads to a rate retardation of 2000- fold for the exo-isomers and 6000 fold for the endo [14] which is comparable to the differences we observed and, indeed, is similar to the effect of oxygen reported for the monocyclic tetrahydrofuranyl ring of $\mathbf{1 0}$ which solvolyses 1030 times more slowly than cyclopentyl brosylate [15].

These effects are much larger than that of oxygen in the 3-position of the tetrahydropyranyl brosylate (11), which slows the rate only by a factor of 18 . However, in this case, participation of oxygen as a neighbouring group is well established [15]. Participation by oxygen in a six-membered ring is excluded for solvolysis of endo (although not exo) norbornyl brosylate substituted with oxygen at the 4-position (12). Comparison with the carbocyclic substrate in this case shows a rate retardation of 80,000 [16]. This value has been considered exceptionally large and an additional rate-retarding effect has been attributed to ring strain induced by the presence of oxygen in the six- 
Table 2: Solvolysis reactions: oxygen substituent effects on reactivity ${ }^{\mathrm{a}}$.

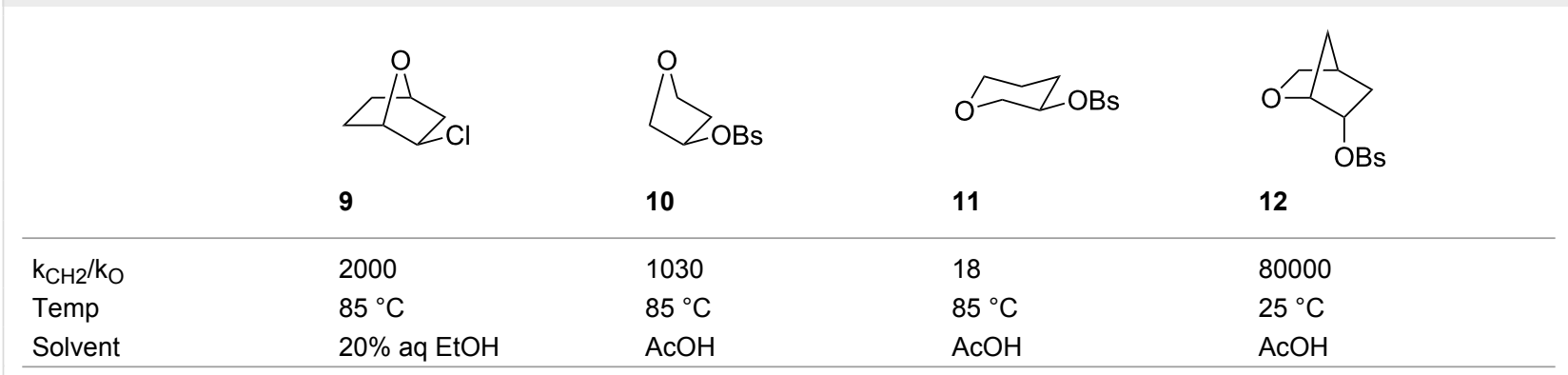

$a_{\text {data from [14-16]. }}$

membered ring of the bicyclic carbocation. Surprisingly, while the solvolysis of trans-2-methoxycyclohexyl tosylate has been well studied [17], there appear to have been no measurements reported for its cis isomer.

We cannot compare these rate ratios directly with those for the solvolyses of cis- and trans-1-trichloroacetoxy-2-methoxydihydronaphthalenes (3) because, as noted in the introduction, the parent 1-trichloroacetoxy-1,2-dihydronaphthalene is too reactive to allow isolation and kinetic measurements. However, rate constants have been measured for the acid-catalysed reactions of cis and trans-naphthalene 1,2-dihydrodiols 13-cis and 13-trans (reacting at the 1-position) and may be compared with the corresponding alcohol lacking a $\beta$-hydroxy substituent, namely the 1-hydroxy-1,2-dihydronaphthalene (14) [3], as shown in Figure 5.

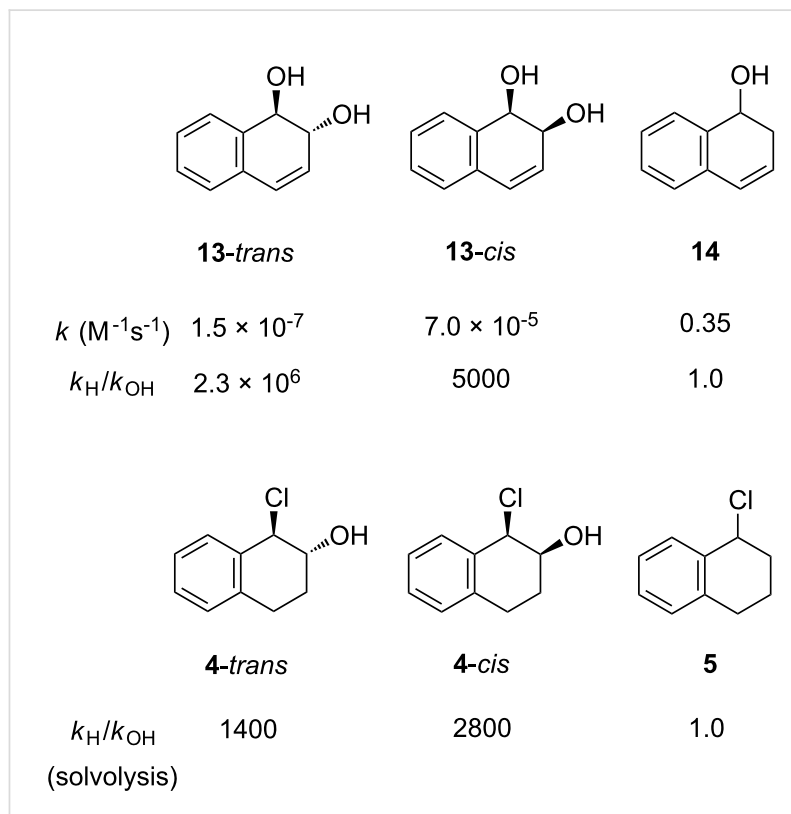

Figure 5: Comparison of the effect of a $\beta$-hydroxy group on the reactivity of cis and trans di- and tetrahdronaphthalene substrates.
It can be seen from this figure that a $\beta$-hydroxy substituent has similar effects on the reactivity of cis-dihydro and tetrahydro substrates, with a rate retarding effect of 5000 for 13 -cis in Figure 5, compared with 2800 for solvolysis of the cis $\beta$-hydroxychlorotetrahydronaphthalene 4 . In contrast, the effect is much greater in the dihydro case for the trans-substituent, i.e., $2.3 \times 10^{6}$ for 13-trans compared with 1400 for solvolysis ot 4-trans. Measurements for benzene and phenanthrene dihydrodiols confirm that, whereas the ratio of $c i s$-rate constants to those of the corresponding alcohols, which lack a $\beta$-hydroxy group, remains roughly constant, those for the trans-dihydrodiols increase sharply as the aromaticity of the double bond increases [18].

These comparisons suggest that that the rate of reaction of the cis-dihydrodiol is 'normal' while that of its trans isomer is abnormally slow. This is consistent with the interpretation already given for the difference in reactivities between the $c i s$ and trans isomers $\mathbf{3}$, namely that the arenium ion intermediates are strongly stabilised by hyperconjugation between the carbocationic charge centre and a $\beta-\mathrm{C}-\mathrm{H}$ bond, and that this effect is amplified by the contribution of an aromatic structure to the no-bond resonance form (15b) of the valence bond representation of this interaction $\mathbf{1 5 a} \leftrightarrow \mathbf{1 5 b}$ in Scheme 4 [3].

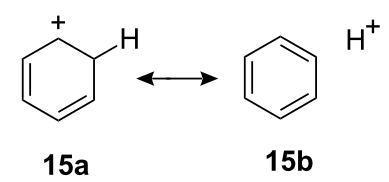

Scheme 4: 'Aromatic' hyperconjugation for the benzenium ion.

The interaction operates effectively for arenium ion intermediates formed from alcohols (arene hydrates) and cis-dihydrodiols or their derivatives which, as illustrated in Scheme 5, can be formed in a conformation in which an axial $\mathrm{C}-\mathrm{H}$ bond bond is positioned for hyperconjugation with the positive charge. 
This is a consequence of a stereochemical constraint requiring that the leaving group departs from an axial position to facilitate delocalisation of the carbocationic charge. However, for the trans-dihydrodiols, or the trans-1-trichloroacetoxy-2-methoxy1,2-dihydronaphthol 3-trans, the same constraint forces the $\beta-\mathrm{OH}$ group into an axial position. Although delocalisation of the charge appears to be highly effective when this position is occupied by a $\beta$-hydrogen atom $(\mathrm{C}-\mathrm{H}$ bond $)$, the interaction becomes very much less favourable when occupied by a $\beta-\mathrm{OH}$ group (C-OH bond).

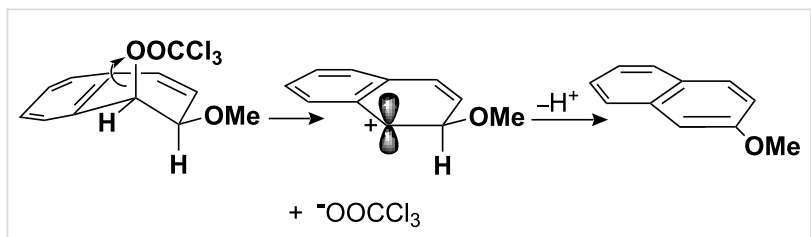

Scheme 5: Stereochemistry of carbocation formation from solvolysis of cis-1-trichloroacetoxy-2-hydroxy-1,2-dihydronaphthalene.

The work describing these favourable and unfavourable hyperconjugative interactions has hitherto been based largely on carbocation formation involving an $\mathrm{H}_{2} \mathrm{O}$ leaving group characteristic of acid-catalysed dehydration of alcohols and cis and trans dihydrodiols of aromatic and aliphatic carbon-carbon double bonds (3). The purpose of the present study was to determine whether the same dependence on stereochemistry of a $\beta$-hydroxy group would be observed for solvolytic reactions. Our conclusion, that it is, is based on a comparison of measurements of absolute and relative reactivities of cis and trans isomers in conventional solvolytic reactions with chloride ion as a leaving group (yielding a carbocation not corresponding to a protonated aromatic molecule) with the solvolytic formation of naphthalenium ions in which the leaving group is a trichloroacetate anion. The only noteworthy difference between the two classes of reactions (i.e., dehydrations and solvolyses) is a slightly larger difference in reactivity between cis and trans methoxy groups for the solvolytically generated arenium ions (2000 compared with 415) which perhaps represents a more product-like transition for the poorer trichloroacetate than the $\mathrm{H}_{2} \mathrm{O}$ leaving group. In sum, the influence of an enhanced hyperconjugation identified in the reactions of arene dihydrodiols is fully corroborated by the present study of $\beta$-hydroxy carbocation-forming solvolysis reactions.

\section{Experimental}

Purchased reagents were generally used without purification. Cis-naphthalene dihydrodiol (cis-1,2-dihydroxy-1,2-dihydronaphthalene) was prepared by oxidative fermentation of naphthalene [19] and was kindly provided by D. R. Boyd of the Queen's University of Belfast. Naphthalene oxide and trans-1- hydroxy-2-methoxy-1,2-dihydronaphthalene (6-trans) were prepared as described by Jerina and co-workers [20]. Trans-1,2dihydroxy-1,2-dihydronaphthalene was prepared by the method of Platt and Oesch [21]. Cis- and trans-1,2-dihydroxy-1,2,3,4tetrahydronaphthalene [22-24], the corresponding trans-1chloro-2-hydroxy-1,2,3,4-tetrahydronaphthalene [25,26] and 1-chloro-1,2,3,4-tetrahydronaphthalene [25] were also prepared by literature methods.

cis-1-Hydroxy-2-methoxy-1,2-dihydronaphthalene (6-cis). To a solution of cis-1,2-dihydroxy-1,2-dihydronaphthalene (0.5 $\mathrm{g}, 3.1 \mathrm{mmol})$ in DMF $(20 \mathrm{~mL})$, was added sodium hydride as a $60 \%$ dispersion on mineral oil $(0.15 \mathrm{~g}, 6.2 \mathrm{mmol})$ followed over $10 \mathrm{~min}$ by dimethyl sulfate $(0.77 \mathrm{~g}, 6.18 \mathrm{mmol})$. The mixture was stirred at room temperature for $20 \mathrm{~h}$, quenched with $1 \mathrm{~mL}$ of acetic acid and diluted with water $(50 \mathrm{~mL})$. It was then extracted with diethyl ether $(2 \times 50 \mathrm{~mL})$ and the combined ether layers washed with water $(2 \times 50 \mathrm{~mL})$ and dried over sodium sulfate. The solvent was removed under reduced pressure to yield a residue consisting of two regioisomeric monomethylated products and the dimethylated product (cis-1,2-dimethoxy1,2-dihydronaphthalene). Purification by chromatography allowed separation of the dimethylated product but the monomethylated products were obtained as a three to one mixture of the desired product with its regioisomer $(0.08 \mathrm{~g}, 15 \%)\left(R_{f} 0.65\right.$, $20 \%$ ethyl acetate in pentane). NMR data for the principal isomer and analytical data for the mixture were as follows.

${ }^{1} \mathrm{H} \mathrm{NMR}\left(\mathrm{CDCl}_{3}\right) \delta 2.6(\mathrm{bs}, 1 \mathrm{H}, \mathrm{OH}), 3.45(\mathrm{~s}, 3 \mathrm{H}), 4.0(\mathrm{t}, J=$ $4.4 \mathrm{~Hz}, 1 \mathrm{H}), 4.78$ (bs, 1H), 6.08 (dd, $J=9.6,3.9 \mathrm{~Hz}, 1 \mathrm{H}), 6.59$ $(\mathrm{dd}, J=9.6 \mathrm{~Hz}, 1 \mathrm{H}), 7.1-7.54(\mathrm{~m}, 4 \mathrm{H}) ; \mathrm{m} / z \mathrm{GC}-\mathrm{MS}) 156$ $\left(\mathrm{M}-\mathrm{H}_{2} \mathrm{O}\right.$ ); (Found $\mathrm{C} 74.3, \mathrm{H} 7.0 ; \mathrm{C}_{11} \mathrm{H}_{12} \mathrm{O}_{2}$ requires $\mathrm{C} 75.0, \mathrm{H}$ 6.9).

cis-1-Trichloracetoxy-2-methoxy-1,2-dihydronaphthalene (3-cis). To a 3:1 mixture (0.1 g, $0.56 \mathrm{mmol})$ of cis-1-hydroxy-2methoxy-1,2-dihydronaphthalene (6-cis) and its regioisomer (see above) in dichloromethane $(10 \mathrm{~mL})$, were added pyridine (45 mg, $0.57 \mathrm{mmol}$ ), DMAP (7 $\mathrm{mg} 0.05 \mathrm{mmol}$ ) and trichloroacetic anhydride $(0.21 \mathrm{~g}, 0.68 \mathrm{mmol})$ and the solution was stirred at room temperature for $2 \mathrm{~h}$. Evaporation of the solvent gave a crude product mixture from which the desired product was separated by flash chromatography $\left(R_{f} 0.61,10 \%\right.$ ethyl acetate in pentane) to give a light yellow oil $(0.08 \mathrm{~g}, 73 \%)$. ${ }^{1} \mathrm{H}$ NMR $\left(\mathrm{CDCl}_{3}\right) \delta 3.4(\mathrm{~s}, 3 \mathrm{H}), 4.31(\mathrm{~m}, 1 \mathrm{H}), 6.05(\mathrm{dd}, J=$ $9.91,2.39 \mathrm{~Hz}, 1 \mathrm{H}), 6.11(\mathrm{~d}, J=4.35 \mathrm{~Hz}, 1 \mathrm{H}), 6.58(\mathrm{dd}, J=$ 9.81, $1.81 \mathrm{~Hz}, 1 \mathrm{H}) 7.15-7.31(\mathrm{~m}, 4 \mathrm{H})$.

trans-1-Trichloracetoxy-2-methoxy-1,2-dihydronaphthalene (3-trans). To a solution of trans-1-hydroxy-2-methoxy-1,2-dihydronaphthalene (6-trans) $(0.1 \mathrm{~g}, 0.56 \mathrm{mmol})$ in 
dichloromethane $(10 \mathrm{~mL})$, pyridine $(45 \mathrm{mg}, 0.57 \mathrm{mmol})$ and DMAP ( $7 \mathrm{mg}, 0.05 \mathrm{mmol}$ ) were added. The mixture was stirred for $5 \mathrm{~min}$ and trichloroacetic anhydride $(0.21 \mathrm{~g}, 0.68 \mathrm{mmol})$ was added over $5 \mathrm{~min}$ followed by stirring for $2 \mathrm{~h}$ at room temperature. Evaporation of the solvent gave a crude product which was purified by preparative TLC ( $5 \%$ ether in pentane) to yield the desired product as a light yellow-coloured liquid (0.14 g 77\%); $\left(R_{f} 0.7310 \%\right.$ ether in hexane); ${ }^{1} \mathrm{H}$ NMR $\left(\mathrm{CDCl}_{3}\right) \delta 3.4(\mathrm{~s}, 3 \mathrm{H})$, 4.29 (ddd, $J=7.53,3.24,1.48 \mathrm{~Hz}, 1 \mathrm{H}$ ), 6.09 (dd, $J=9.87,3.32$ $\mathrm{Hz}, 1 \mathrm{H}), 6.28(\mathrm{~d}, J=7.55 \mathrm{~Hz}, 1 \mathrm{H}), 6.59(\mathrm{dd}, J=9.89,1.00 \mathrm{~Hz}$, 1H) $7.15-7.31(\mathrm{~m}, 4 \mathrm{H}) ; \mathrm{m} / \mathrm{z}$ (GC-MS) $158.1 \quad(321.5$ $\left.-\mathrm{Cl}_{3} \mathrm{CCOOH}\right)$.

cis-1-Chloro-2-hydroxy-1,2,3,4-tetrahydronaphthalene. A solution containing $0.05 \mathrm{~mL}$ of $4 \mathrm{M} \mathrm{HCl}$ in anhydrous dioxane and $0.2 \mathrm{~mL}$ of anhydrous THF was added dropwise to a solution of tetrahydronaphthalene-1,2-oxide (100 $\mathrm{mg}, 0.68 \mathrm{mmol})$ in anhydrous THF $(2 \mathrm{~mL})$ and the mixture allowed to stand at room temperature for $10 \mathrm{~min}$. The solvent and excess $\mathrm{HCl}$ were then removed under reduced pressure to yield a crude product which was purified by TLC $(10 \%$ ether in pentane) to give a colourless liquid (40 mg, 32\%); ${ }^{1} \mathrm{H}$ NMR $\left(\mathrm{CDCl}_{3}\right) \delta 1.96(\mathrm{~m}$, $1 \mathrm{H}), 2.09(\mathrm{~m}, 2 \mathrm{H}), 2.91(\mathrm{~m}, 2 \mathrm{H}), 3.1(\mathrm{~m}, 1 \mathrm{H}), 4.12(\mathrm{~m}, 2 \mathrm{H})$, $5.33(\mathrm{~d}, J=3.0 \mathrm{~Hz}, 1 \mathrm{H}), 7.11-7.37(\mathrm{~m}, 4 \mathrm{H}) ;{ }^{13} \mathrm{C} \mathrm{NMR}\left(\mathrm{CDCl}_{3}\right)$ 26.56, 27.82, 65.55, 69.14,126.44, 128.85, 128.87, 130.71, 134.56, 135.57; m/z (GC-MS) 182.5.

Kinetic measurements and product ratios. In general, rate constants for solvolysis reactions were measured by injecting $20-25 \mu \mathrm{L}$ of a $\sim 0.01 \mathrm{M}$ solution of substrate in acetonitrile into $2 \mathrm{~mL}$ of water or aqueous acetonitrile in a cuvette and monitoring the reaction from the change in the UV spectrum. For 1-chloro-1,2,3,4-tetrahydronaphthalene rate constants $\left(\mathrm{s}^{-1}\right)$ were measured for the following acetonitrile water solvent mixtures: $50 \% \mathrm{MeCN}, 0.0320 ; 60 \% \mathrm{MeCN}, 0.0106 ; 70 \%$ $\mathrm{MeCN}, 0.00335 ; 80 \% \mathrm{MeCN}, 0.00082$. A plot of $\log k$ versus $Y_{\mathrm{OTs}}$ and extrapolation gave a rate constant of $\sim 2.3 \mathrm{~s}^{-1}$ for pure water.

For both the trichloroacetate esters of 2-methoxy-1,2-dihydro-1naphthol and the cis-and trans-chlorohydrins of 1,2-dihydronaphthalene product analyses were carried out by HPLC. In a typical procedure $25 \mu \mathrm{L}$ of $\sim 0.01 \mathrm{M}$ solution of the substrate in acetonitrile were injected into $150 \mu \mathrm{L}$ of water or aqueous acetonitrile mixture. After allowing time for completion of the reaction, the products were analysed by reverse phase HPLC on a $\mathrm{C} 18$ column with a flow rate of $0.25 \mathrm{~mL} / \mathrm{min}$ and detection at $270 \mathrm{~nm}$. For the trichoroacetic esters, the product proportions were required to partition measured rate constants between contributions from pathways for solvolysis and hydrolysis.

\section{Supporting Information}

\section{Supporting Information File 1}

Experimental part.

[http://www.beilstein-journals.org/bjoc/content/

supplementary/1860-5397-6-118-S1.pdf]

\section{Acknowledgements}

This work was supported by The Science Foundation Ireland (Grant No. 04/IN3/B581). We thank A. Cagney for assistance with the kinetic measurements.

\section{References}

1. Boyd, D. R.; Bugg, T. D. Org. Biomol. Chem. 2006, 4, 181-192. doi:10.1039/b513226f

2. Boyd, D. R.; Blacker, J.; Briege, B.; Dalton, H.; Hand, M. V.; Kelly, S. C.; More O'Ferrall, R. A.; Rao, S. N.; Sharma, N. D.; Sheldrake, G. N. J. Chem. Soc., Chem. Commun. 1994, 313-314. doi:10.1039/C39940000313

3. Boyd, D. R.; Coyne, D.; Keeffe, J. R.; Kudavalli, J. S.; Lawlor, D. A.; MacCormac, A. C.; More O'Ferrall, R. A.; Rao, S. N.; Sharma, N. D. Org. Lett., in press.

4. Bentley, T. W.; Llewellyn, G. $Y_{x}$ Scales of Solvent lonizing Power. In Prog. Phys. Org. Chem.; Taft, R. W., Ed.; John Wiley \& Sons, Inc.: Hoboken, NJ, USA, 1990; Vol. 17, pp 121-158. doi:10.1002/9780470171967.ch5

5. Bunton, C. A.; Mhala, M. M.; Moffatt, J. R. J. Org. Chem. 1984, 49, 3637-3639. doi:10.1021/jo00193a036

6. Pirinccioglu, N.; Thibblin, A. J. Am. Chem. Soc. 1998, 120, 6512-6517. doi:10.1021/ja9807800

7. Lawlor, D. A.; More O'Ferrall, R. A.; Rao, S. N. J. Am. Chem. Soc. 2008, 130, 17997-18007. doi:10.1021/ja806899d

8. Kudavalli, J. S.; More O'Ferrall, R. A. Unpublished results.

9. Streitwieser, A., Jr. Solvolytic Displacement Reactions; McGraw-Hill: New York, 1962.

10. Winstein, S.; Grunwald, E.; Ingraham, L. L. J. Am. Chem. Soc. 1948, 70, 821-828. doi:10.1021/ja01182a113

11. Winstein, S.; Grunwald, E. J. Am. Chem. Soc. 1948, 70, 828-837. doi:10.1021/ja01182a114

12. Capon, B.; McManus, S. P. Neighbouring Group Participation; Plenum Press: London, U. K., 1976.

13. Perst, H. Oxonium lons in Organic Chemistry; Academic Press: London, U. K., 1971.

14. Martin, J. C.; Bartlett, P. D. J. Am. Chem. Soc. 1957, 79, 2533-2541. doi:10.1021/ja01567a047

15. Tarbell, D. S.; Hazen, J. R. J. Am. Chem. Soc. 1969, 91, 7657-7663. doi:10.1021/ja50001a023

16. Spurlock, L. A.; Fayter, R. G., Jr. J. Am. Chem. Soc. 1972, 94, 2707-2711. doi:10.1021/ja00763a027

17. Roberts, D. D. J. Org. Chem. 1997, 62, 1857-1859. doi:10.1021/jo961941q

18. MacCormac, A. C.; Lawlor, D. A.; More O'Ferrall, R. A. Unpublished results.

19. Jerina, D. M.; Daly, J. W.; Jeffrey, A. M.; Gibson, D. T. Arch. Biochem. Biophys. 1971, 142, 394-396. doi:10.1016/0003-9861(71)90298-0 
20. Jeffrey, J. M.; Yeh, H. J. C.; Jerina, D. M.; DeMarinis, R. M.;

Foster, C. H.; Piccolo, D. E.; Berchtold, G. A. J. Am. Chem. Soc. 1974,

96, 6929-6937. doi:10.1021/ja00829a020

21. Platt, K. L.; Oesch, F. Synthesis 1977, 449-450.

doi:10.1055/s-1977-24434

22. Orsini, F.; Sello, G.; Travaini, E.; Di Gennaro, P

Tetrahedron: Asymmetry 2002, 13, 253-259.

doi:10.1016/S0957-4166(02)00098-8

23. Sukumaran, K. B.; Harvey, R. G. J. Org. Chem. 1980, 45, 4407-4413. doi:10.1021/jo01310a029

24. Boyd, D. R.; Sharma, N. D.; Kerley, N. A.; McConville, G.; Allen, C. C. R.; Blacker, A. J. ARKIVOC 2003, 7, 32-48.

25. Bartas-Yacoubou, J.-M.; Maduike, N.; Kyere, S.; Doan, L.; Whalen, D. L. Tetrahedron Lett. 2002, 43, 3781-3782. doi:10.1016/S0040-4039(02)00637-8

26. Reimann, E.; Hargasser, E. Arch. Pharm. 1989, 322, 159-164. doi:10.1002/ardp.19893220309

\section{License and Terms}

This is an Open Access article under the terms of the Creative Commons Attribution License

(http://creativecommons.org/licenses/by/2.0), which permits unrestricted use, distribution, and reproduction in any medium, provided the original work is properly cited.

The license is subject to the Beilstein Journal of Organic Chemistry terms and conditions:

(http://www.beilstein-journals.org/bjoc)

The definitive version of this article is the electronic one which can be found at: doi:10.3762/bjoc. 6.118 